Bioscientia Medicina: Journal of Biomedicine \& Translational Research

Journal Homepage: www.bioscmed.com

\title{
Risk, Causality and Management of Severe Allergic Reactions of RNA Messenger SARS-CoV-2 Vaccine: A Mini Review
}

\section{Dwitya Elvira ${ }^{*}$, Raveinal ${ }^{1}$}

${ }^{1}$ Allergy Immunology Subdivision, Department of Internal Medicine, Faculty of Medicine, Andalas University/ Dr. M. Djamil General Hospital, Padang, Indonesia

\section{A R T I C L E I N F O \\ Keywords: \\ Anaphylaxis \\ Covid-19 \\ mRNA vaccine \\ Polyethylene glycol \\ Severe allergy reaction \\ *Corresponding author: \\ Dwitya Elvira \\ E-mail address: \\ dwitya.elvira@yahoo.com}

All authors have reviewed and approved the final version of the manuscript.

\begin{abstract}
A B S T R A C T
SARS-CoV-2 infection has become a health problem throughout the world, including Indonesia with high rates of morbidity (more than 3 million confirmed case) and mortality (more than 80 thousand) due to COVID-19 since it was announced as pandemic in March 2020. Vaccination is one of the efforts to eliminate the pandemic, and just recently Food and Drug Monitoring Agency (BPOM) and Indonesian Government have granted approval for emergency use of messenger RNA (mRNA)-based vaccines. Allergic reactions after vaccination are rare adverse events, including severe allergic reactions and anaphylaxis. Polyethylene glycol (PEG) in mRNA vaccines is thought to be a hidden allergen that trigger allergies. Screening of individuals with a previous history of allergies is necessary to prevent reaction. Experienced health workers are also needed to provide adequate management in the event of a severe allergic reaction or anaphylaxis after COVID-19 vaccination. Aim of this review is to look at the risk of allergy of mRNA vaccine SARS CoV-2; possible causes of allergies and management of individuals with severe allergies/anaphylaxis.
\end{abstract}

https://doi.org/10.37275/bsm.v6i4.475

\section{Introduction}

The Indonesian Food and Drug Monitoring Agency (BPOM) has just given Emergency Use of Authorization (EUA) to two messenger RNA (mRNA) vaccines, namely BNT162b2 mRNA and mRNA-1273 vaccines as SARSCoV-2 vaccines in July 2021.1,2 Both vaccines had previously been approved for emergency use in United Kingdom, Bahrain, Canada, Mexico, United States, Singapore, Oman, Saudi Arabia, Kuwait, European Union for BNT162b2 vaccine and in United States and Canada for mRNA-1273 vaccine. ${ }^{3}$

The mRNA-1273 (Moderna) vaccine is currently planned to be used in approximately 1.5 million health workers as the third dose of vaccine to provide immunity to existing viral mutations, one of which is the delta variant, which was also approved by Indonesian Technician Advisory Group of Immunization (ITAGI) and Health Ministry of Indonesia. 4

Reports of clinical trials conducted on both vaccines, the adverse events that occur are low risk, but after mass vaccination, it was reported that there was a severe allergic reaction in the form of anaphylaxis 
in 2 health workers and CDC reported several severe allergy events that were suspected to be related to the vaccine. ${ }^{5}$ This literature review was aimed to explore the risk, causality or the most likely cause of allergies from the vaccine as well as screening and treatment if an unexpected reaction occurs from the vaccine.

\section{Risk of allergy reactions}

The current COVID-19 vaccination is one of the hopes to eliminate the pandemic quickly, so that more than 200 vaccines from various platforms have been developed, such as inactivated vaccines, messenger RNA (mRNA), viral vector vaccines, protein sub-unit vaccines and various other vaccines platforms. ${ }^{6}$ Recently, Indonesia through BPOM has given approval for the use of the SARS-CoV-2 vaccine with messenger RNA (mRNA) platform, namely the BNT162b2 vaccine produced by Pfizer and BioNTech and mRNA-1273 produced by Moderna in July 2021. The use of this vaccine previously been used in Europe and Asia countries. ${ }^{3,4}$

The Ministry of Health of the Republic of Indonesia has determined the use of the Moderna mRNA vaccine to be used as a third dose of vaccine for health workers considering the importance of additional vaccination due to new variants that have emerged with the ability to spread faster and high virulence levels. ${ }^{4}$

Allergic reactions to vaccines, including anaphylaxis, are a rare adverse event reaction (AEFI), which is estimated to occur around 1-10 per 1 million doses of injected vaccine and is usually caused by the presence of excipients, adjuvants and or other components contained in the vaccine itself. ${ }^{7}$ Reports in Europe and America regarding the use of mRNA vaccines show that there is a risk of anaphylactic reactions with 2 cases of anaphylaxis in the UK and 6 cases in the United States after mass vaccination with Pfizer vaccine. The same report in January 2021 also showed that there were 108 cases of severe allergy reaction with 10 cases being anaphylactic reactions after 4,041,396 Moderna vaccinations were injected. Collaborative data showed that there were 21 anaphylaxis events with details of 18 cases appearing immediately after the vaccine was injected (the first 30 minutes), 4 cases requiring hospitalization and 17 cases being admitted to the emergency room. ${ }^{8}$ No deaths were reported as a result of this anaphylactic event. The median time to anaphylaxis was 7.5 minutes (1-45 minutes) from the start of the vaccine injection. The report also shown that anaphylactic reactions were more common in women than men $(100 \%$ for vaccine mRNA-1273 and 90\% for vaccine BNT162b2) for reasons that are still unclear. As many as $81 \%$ of patients with anaphylaxis reported having a history of allergies to food, contrast drugs and insect bites, while $41 \%$ of patients (7 of 14 people) had a history of previous anaphylaxis including reactions to vaccines. ${ }^{9,10,11}$

\section{mRNA vaccines and ingredients}

The development of mRNA vaccines has started since the development of vaccines for Ebola, Zika, and rabies virus infections and is currently used as one of the COVID-19 vaccine platforms. The mRNA vaccine is a vaccine developed with recombinant genetic technology utilizing genetic material in the SARS-CoV2 virus known as spike protein which is able to trigger an immune reaction against COVID-19.12

The content of the vaccine is shown in Fig. 1 where each vaccine consists of an active component and an excipient. The active component is mRNA that encodes the spike protein that causes SARS-CoV-2 infection and when injected directly without excipient components it will stimulate the mRNA to be absorbed by mononuclear phagocytic cells and will be rapidly degraded by ribonucleases making it difficult to penetrate to the cells. The excipient component is needed as a protective/shield mRNA which is usually in the form of lipid base nanoparticles (LNP). The cation lipid will coat the polyanionic mRNA; cholesterol will act as a stabilizer of the nanoparticle lipid bilayer. Meanwhile, modified PEG (polyethylene glycol) act as a hydration layer which increases the liquid solubility of LNP. This excipient component able to stimulate activation of antigen presenting cells (APC), resulting in upregulation of molecules essential for antigen presentation, such as MHC class II (antigen-specific signal-1) and B7-1/2 and the production of pro- 
inflammatory cytokines (nonspecific signal 2). These innate immune events allow the administered antigen to be processed and presented to the adaptive immune

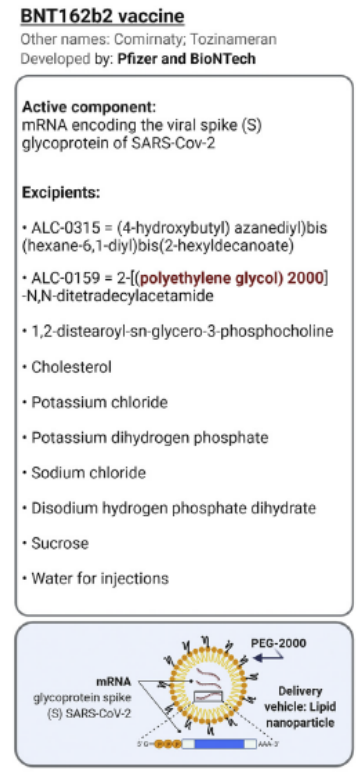

Figure 1. Active and excipient composition of mRNA vaccine. ${ }^{9}$ system more effectively, resulting in the augmented activation and greater clonal expansion of $T$ cells. ${ }^{13,14,15,16}$

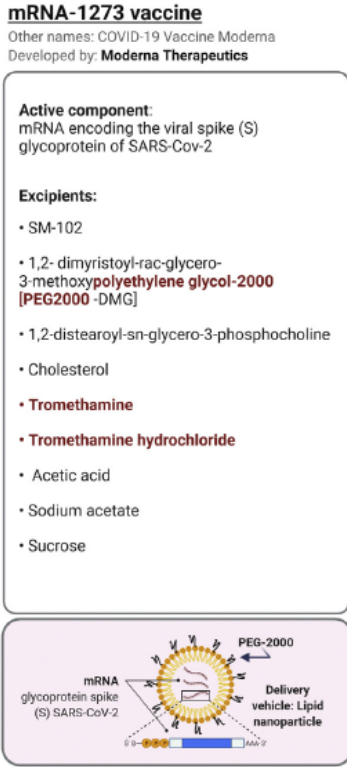

\section{Possible causality of allergic reactions}

The suspected cause of allergic and anaphylactic reactions is the excipient component, name as polyethylene glycol (PEG). PEG, also known as macrogol, is a polyether component that is commonly used as an additive in cosmetic, pharmaceutical and food industries. The use of PEG in mRNA vaccines is intended to maintain stability and protection and can increase the immune response to the vaccine. PEG has a molecular weight of $200-10,000,000 \mathrm{~g} / \mathrm{mol}$. Allergic reactions have been reported to be associated with the use of PEG in drugs and cosmetics, so that PEG is thought to potential to be an allergenic component in vaccines. 17

The mRNA vaccine also contains polysorbate 80 which has a molecular weight of $1,310 \mathrm{~g} / \mathrm{mol}$ so with this low molecular weight it is less likely to be caused by an allergy reaction. Polysorbate80 has been used in previous vaccines such as influenza, hepatitis, so the use of PEG which has a similar molecular structure $\left(\left(\mathrm{CH}_{2}-\mathrm{CHO}\right)_{n}\right)$ allows cross-reactivity, although it rarely occurs. ${ }^{18}$

The exact mechanism of allergic reactions due to PEG is still unclear. Patients with a history of PEG anaphylaxis show high levels of IgE antibodies to PEG. The binding of IgE with PEG allergens to form IgE-FcR1 complexes in mast cells or basophils stimulates the release of histamine, prostaglandins and proteases that trigger an anaphylactic reaction. In general, clinical symptoms of anaphylaxis appear within minutes to an hour after exposure to the allergen. or antigens in vaccines. The results of in vitro studies also show that PEG can trigger complement activation thereby activating the CARPA condition, but these results are still inconclusive in human subjects. ${ }^{19}$

\section{Screening and management of severe allergy}

COVID-19 vaccination is aimed to increasing herd immunity which can be achieved if vaccination coverage reaches $>60 \%$ of the total population. With the possibility of mild to severe allergic reactions including anaphylaxis after vaccination, it is necessary to screen and evaluate the history of allergies in people who will be vaccinated. History of drug allergy, food and manifestations that appear such as urticaria, rash, angioedema, sensation of throat swelling, shortness of breath or anaphylactic shock should be asked at the beginning of the examination. Patients with a history of 
allergies are not contraindicated in mass vaccination against COVID-19, but preparation from the outset in recognizing and treating anaphylaxis is necessary, especially within first 15 to 30 minutes after vaccination. Two things that are important for the safety of vaccination are (i) patients with a history of anaphylaxis or severe allergies should be observed 30 minutes after vaccination, (ii) individuals with a history of vaccine allergy should be screened for allergies either by skin prick test or intradermal test to determine the cause of the allergy. 20,21

Skin prick test or intradermal test can be done using PEG material or vaccines containing polysorbate 80 (Hepatitis or TwinRix). Skin prick test may start with dilution of PEG and polysorbate 1:100; 1:10 dan $1: 1$ respectively every 30 minute with histamin $1: 1$ as positive control and gliserin 1:1 as negative control. Intradermal test using depo medrol (metilprednisolon asetat) $40 \mathrm{mg} / \mathrm{ml}$ and triamcinolon acetonide 40 $\mathrm{mg} / \mathrm{ml}$ with dilution every 30 minutes, $1: 100$ dan $1: 10$ respectively and continue with observation for one hour. A number of tests can be performed on people who are suspected to have a previous history of allergies or are known to be allergic to ingredients containing PEG.22 In addition, a basophil activation test and an oral provocation test can also be performed.

Preparations that are important in the management of severe allergic reactions/anaphylaxis are injections of IM epinephrine with adequate doses (can be repeated if the condition has not been treated) by keeping the patient in a resting position, oxygen (facial mask oxygen), $0.9 \% \quad$ IV NaCL fluids, medication antihistamines and corticosteroids and close monitoring of anaphylactic conditions ${ }^{23}$. The steps taken in the management of anaphylaxis are as follows: position the patient in a supine position with the legs elevated, prepare for epinephrine IM injection. Prepare intravenous fluids of $0.9 \% \mathrm{NaCL}$ to replace fluid volume; Clean the airway, check vital signs, prepare oxygen via facial mask $10 \mathrm{~L} /$ minute; Intravenous fluids $0.9 \%$ NaCL $2-3$ L for 10-20 minutes if the patient is hypotensive or is losing fluid volume rapidly; Repeat IM epinephrine 5-10 minutes later if there is no clinical improvement.
Mast cell tryptase examination can be performed 23 hours after the initial reaction to confirm the occurrence of anaphylaxis. It is important to distinguish this anaphylactic reaction from a vasovagal reaction, where a vasovagal reaction usually occurs seconds or minutes after injection of the vaccine accompanied by symptoms of nausea, vomiting, dizziness with slow breathing, slow and weak but regular pulse. In addition, mass vaccination preparation also includes an anaphylaxis management algorithm starting from a screening, monitoring and evaluation process that requires experienced health workers. ${ }^{24}$

\section{Conclusion}

The risk of severe allergy/anaphylaxis is a rare reaction after vaccination. This type of reaction is usually rapid within 15-30 minutes after the vaccine so close monitoring is needed in people who have a history of previous allergies. Provision of emergency drugs for the management of anaphylaxis is needed in health facilities with experienced staff in carrying out vaccination programs to avoid the possibility of this severe allergic reaction occurring.

\section{References}

1. (BPOM) Food and Drug Monitoring Agency. The POM Agency publishes the EUA Moderna Covid19 vaccine as the first vaccine from the mRNA platform. Retrieved August 1, 2021 from https://www.pom.go.id/new/view/more/pers/61 5/Badan-POM-Terbitkan-EUA-Moderna-COVID-

19-Vaccine-As-Vaccine-Pertama-dari-PlatformmRNA. html.

2. (BPOM) Food and Drug Monitoring Agency. The POM Agency publishes the EUA Comirnaty as the second vaccine for the mRNA platform. Retrieved August $\quad 1, \quad 2021$ from https://www.pom.go.id/new/view/more/pers/61 8/Badan-POM-Terbitkan-EUA-Comirnaty-Vaksin-COVID-19-Pfizer---As-Vaccine-SecondPlatform -mRNA.html. 
3. Selvaraj G, Kaliamurthi S, Peslherbe GH, Wei DQ. Are the allergic reactions of COVID-19 vaccines caused by mRNA constructs or nanocarriers? Immunological insights. Interdiscip Sci Comput Life Sci. 2021; 13: 344-7. https://doi.org/10.1007/s12539-021-00438-3

4. Covid-19 Task Force. The arrival of the 20th stage of the vaccine is not only for the public, but also for the modern vaccine for the 3rd dose of health workers. Retrieved July 11, 2021 from https://covid19.go.id/p/berita/kecepatanvaksin-cepat-ke-20-selain-for-Rumah-vaksinmoderna-juga-untuk-dosis-ke-3-energikesehatan.

5. Kelso JM. Misdiagnosis of systemic allergic reactions to mRNA COVID-19 vaccines. Ann Allergy Asthma Immunol. 2021; 127: 131-51. https://doi.org/10.1016/j.anai.2021.03.024.

6. Calina D, Sharkar C, Arsene AL, Salehi B, Docea AO, Mondal M. Recent advances, approaches and challenges in targeting pathways for potential COVID-19 vaccines development. Immunol Res. 2020; 68(6): 315-24. https://doi.org/10.1007/s12026-020-09154-4.

7. Ezquerra RP, Quiros C, Molina T, Ocarz B, Ortuno Z. Safety of new mRNA vaccines against Covid-19 in severely allergic patients. $\mathrm{J}$ Investigating Allergol Clin Immunol. 2021; 31(2): 180-1. https://doi.org/10.18176/jiaci.0683.

8. Paoletti G, Racca F, Piona A, Melone G, Merigo M, Puggioni F. Successful SARS-CoV-2 vaccine allergy risk management: the experience of large Italian University Hospital. World Allergy Organization Journal. 2021; 1-10. http://doi.org/10.1016/j.waojou.2021.100541.

9. Cabanillas B, Novak N. Allergy to Covid-19 vaccines: a current update. Allergiology International. 2021; 70: 313-8. https://doi.org/10.1016/i.alit.2021.04.003

10. CDC COVID-19 Response Team, Administration FDA. Allergic reactions including anaphylaxis after receipt of the first dose of Pfizer-BioNTech COVID-19 vaccine - United States, December 14-
23, 2020. MMWR Morb Mortal Wkly Rep 2021; 70: 46e51.https://doi.org/10.1111/ajt.16516.

11. CDC COVID-19 Response Team, Administration FDA. Allergic reactions including anaphylaxis after receipt of the first dose of Moderna COVID-19 vaccine - United States, December 21, 2020January 10, 2021. MMWR Morb Mortal Wkly Rep 2021; 70: 125e9. Accessed online from https://www.cdc.gov/mmwr/volumes/70/wr/m m7004e1.htm.

12. Abassi J. Covid-19 and mRNA vaccines-first large test for a new approach. JAMA. 2020; 324(12): 1125-7.https://doi:10.1001/jama.2020.16866.

13. Meo SA, Bukhari IA, Akram J, Meo AS, Klonoff DC. Covid-19 vaccines: comparison of biological, pharmacological characteristics and adverse effects of Pfizer/BioNTech and moderna vaccines. European Review for Medical and Pharmacological Sciences. 2021; 25: 1663-9. doi: 10.26355/eurrev_202102_24877.

14. Klimek L, Novak N, Hamelmann E, Werfel T, Wagenmann M, Taube $\mathrm{C}$ et al. Severe allergic reactions after COVID-19 vaccinations with the Pfizer/BioNTech vaccine in Great Britain and USA. Allergo J Int. 2021; 30: 51-5. https://doi.org/10.1007/s40629-020-00160-4

15. Cabanillas B, Akdis CA, Novak N. Allergic reactions to the first COVID-19 vaccine: a potential role of polyethylene glycol. Allergy. 2021; 76: 1617-18. doi: 10.1111/all.14711.

16. Shoenfeld Y, Agmon-Levin N, Tomljenovic L. Vaccines and autoimmunity. Wiley Blackwell. 2015: 1-392.

17. Turk VE. Anaphylaxis associated with the mRNA Covid-19 vaccines: approach to allergy investigation. Clinical Immunology. 2021; 227(108748): 1-6. https://doi.org/10.1016/i.clim.2021.108748

18. Paoletti G, Racca F, Piona A, Melone G, Merigo M, Puggioni F. Successful SARS-CoV-2 vaccine allergy risk management: the experience of large Italian University Hospital. World Allergy Organization Journal. 2021; 1-10, http://doi.org/10.1016/i.waojou.2021.100541. 
19. Kounis NG, Koniari I, Gregorio C, Velissaris D, Petalas K, Brinia A et al. Allergic reactions to currently available Covid-19 vaccinations: pathophysiology, causality and therapeutic considerations. Vaccines. 2021; 9(221): 1-19. https://doi.org/10.3390/vaccines9030221

20. Peter J. Covid-19 vaccination: recommendation for management of patients with allergy or immune based diseases. S Afr Med J. 2021; 111(4): 291-4. DOI: $10.7196 /$ SAMJ.2021.v111i4.15576

21. Abi Zeid Daou C, Natout MA, El Hadi N. Biphasic anaphylaxis after exposure to the first dose of Pfizer-Biontech Covid-19 mRNA vaccines. J Med

Virol. 2021; 1-3. doi: 10.1002/jmv.27109

22. Tumer PJ, Ansotegui IJ, Campbell DE, Cardona V, Ebisawa M, El-Gamal Y et al. Covid-19 vaccineassociated anaphylaxis: a statement of the World Allergy Organization Anaphylaxis Committee. World Allergy Organization Journal. 2021; 14(100517): 1-10. http://doi.org/10.1016/j.waojou.2021.100517

23. Nillsson L, Csuth A, Storsaeter J, Garvey LH, Jenmalm MC. Vaccine allergy: evidence to consider for Covid-19 vaccine. Curr Opin Allergy Clin Immunol. 2021; 21: 401-9. DOI: 10.1097/ACI.0000000000000762

24. Tanno LK, Berard F, Beaudoin E, Didier A, Demoly P. SARS-CoV-2 vaccination and anaphylaxis: recommendations of the Frech allergy community and the Montpellier WHO collaborating center. Vaccines. 2021; 9(560): 1-13. https://doi.org/10.3390/vaccines9060560. 